Available online at www.sciencedirect.com ScienceDirect
Research in

Autism Spectrum Disorders

\title{
A review of neuropsychological and neuroimaging research in autistic spectrum disorders: Attention, inhibition and cognitive flexibility
}

(1)

\author{
Jane Sanders $^{\mathrm{a}}$, Katherine A. Johnson ${ }^{\mathrm{b}, *}$, Hugh Garavan ${ }^{\mathrm{b}}$, \\ Michael Gill ${ }^{\text {a }}$, Louise Gallagher ${ }^{\mathrm{a}}$ \\ ${ }^{a}$ School of Medicine and Health Sciences and Trinity College Institute of Neuroscience, \\ Trinity College Dublin, Dublin 2, Ireland \\ ${ }^{\mathrm{b}}$ School of Psychology and Trinity College Institute of Neuroscience, Trinity College Dublin, Dublin 2, Ireland
}

Received 20 February 2007; received in revised form 8 March 2007; accepted 26 March 2007

\begin{abstract}
Autistic spectrum disorders (ASD) are devastating neurodevelopmental disorders of unknown aetiology with characteristic deficits in social interaction, communication and behaviour. Individuals with ASD show deficits in executive function (EF), which are hypothesised to underlie core repetitive, stereotyped behaviours of autism. Neuroimaging research has identified structural brain abnormalities in ASD, which coincide with brain regions involved in EF. Therefore, we reviewed the literature on four specific executive functions in ASD — sustained attention, orienting attention, response inhibition and set shifting. Medline and Embase searches were carried out using specific search terms. This task was followed by the identification of further relevant publications from papers referenced in initial search results. Discussion with experts in neuropsychology, neuroimaging and autism research yielded further publications that were reviewed. Based on these data there is evidence to suggest that deficits in orienting attention, response inhibition and set shifting exist in ASD, but sustained attention ability appears to be normal. A striking lack of research attempting to link neural correlates with these deficits in orienting attention, response inhibition and set shifting was noted. Future research should focus on understanding links between the neuropsychological deficits and structural and functional brain abnormalities.
\end{abstract}

(C) 2007 Published by Elsevier Ltd.

Keywords: Autism; Executive function; Cognitive flexibility; Sustained attention; Orienting attention; Response inhibition; Neuropsychology; Imaging

* Corresponding author at: School of Psychology, Trinity College Dublin, College Green, Dublin 2, Ireland.

Tel.: +3531896 8403; fax: +35316712006.

E-mail address: johnsoka@tcd.ie (K.A. Johnson).

1750-9467/\$ - see front matter (C) 2007 Published by Elsevier Ltd.

doi: $10.1016 /$ j.rasd.2007.03.005 


\section{Contents}

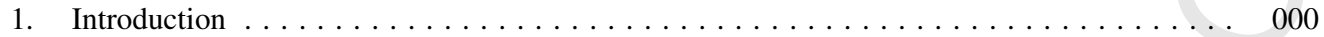

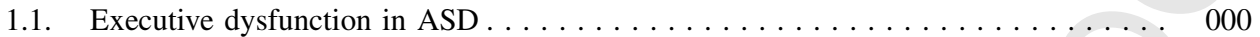

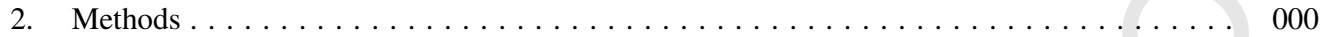

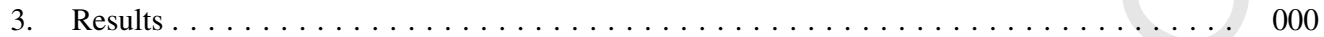

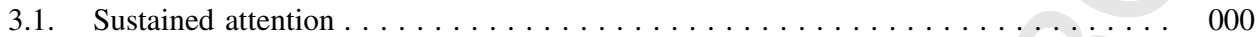

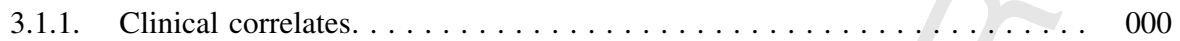

3.1.2. Neuropsychological studies . . . . . . . . . . . . . . . . . . . . . 000

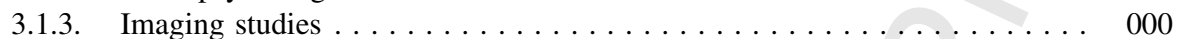

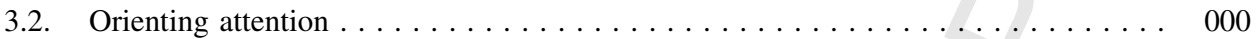

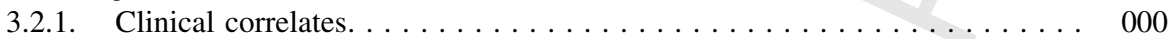

3.2.2. Neuropsychological studies . . . . . . . . . . . . . . . . . . . 000

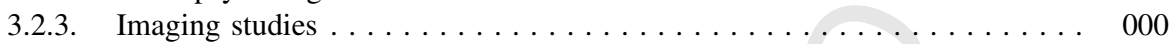

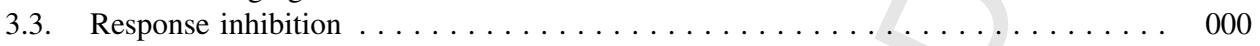

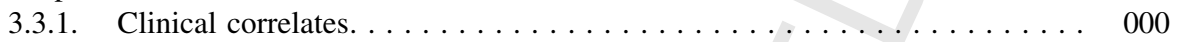

3.3.2. Neuropsychological studies . . . . . . . . . . . . . . . . . . 000

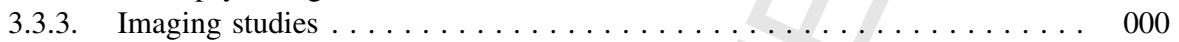

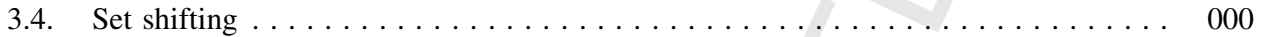

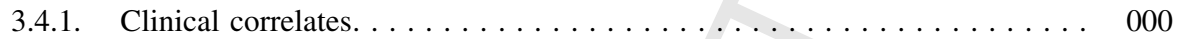

3.4.2. Neuropsychological studies . . . . . . . . . . . . . . . . . . . . 000

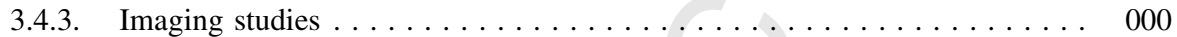

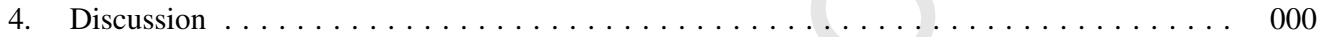

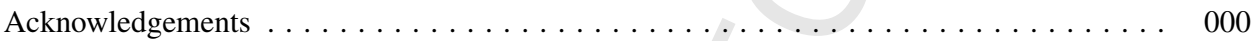

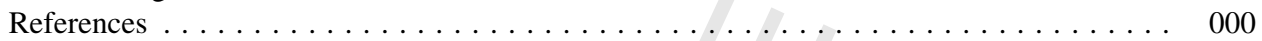

\section{Introduction}

Autistic spectrum disorders (ASD) are devastating neurodevelopmental disorders of childhood with deficits in social interaction and communication and characteristic restricted, repetitive patterns of behaviours, interest and activities. Autism, Retts' disorder, childhood disintegrative disorder, pervasive developmental disorder-not otherwise specified and asperger syndrome are classified in ICD-10 and DSM-IV as the five pervasive developmental disorders (PDD). The term ASD is commonly used clinically to describe conditions on the autistic spectrum not meeting the strict criteria for autism as defined by ICD-10 or DSM-IV. Within the confines of this review, we are including autism, high-functioning autism and Asperger syndrome within the boundaries of the term ASD. Asperger syndrome describes individuals with core deficits in social interaction, communication and behaviour with normal intellectual functioning and no history of speech and language delay. High functioning autism commonly refers to individuals meeting criteria for autism with normal intellectual functioning and a history of speech and language delay. Most neuropsychological and neuroimaging research involves testing children with a diagnosis of Asperger syndrome or high functioning autism rather than autism, in which a substantial number of the children suffer from intellectual disability as well; at least in part because of the greater ability of the children with Asperger syndrome or high functioning autism to complete the study tasks.

Autism has a population prevalence of 1/1000 while other ASDs are relatively frequent with prevalence rates in the order of 1 in 250 (Fombonne, 2003). The deficits associated with autism 
are enduring. Co-morbid features, such as depression, anxiety, obsessional features and oppositionality, frequently complicate the clinical picture and cause difficulties with clinical management. An improved understanding of the underlying pathophysiology of the disorders will aid the discovery of novel treatments.

Although the cause of autism remains unknown, it is widely accepted that there is a strong genetic component (Bailey et al., 1995). The mode of inheritance is unclear, but it is widely considered to be an oligo-genic disorder with 5-15 susceptibility genes of small effect size (Pickles et al., 1995; Risch et al., 1999). Large-scale genetic studies are ongoing in an effort to identify susceptibility genes for autism (International Molecular Genetic Study of Autism Consortium, 2001; The Autism Genome Project and Consortium, in press). Understanding the complex relationships between genotype and phenotype is a current challenge.

In parallel with genetic research, neuropsychologists have been attempting to understand the relationship between brain structures and the psychological and behavioural functions they serve. Although this relationship is still quite unclear, it is widely accepted that there are specific neuropsychological deficits in autism. It is hoped that increased understanding of these cognitive deficits will lead to better definitions of specific cognitive phenotypes (or endophenotypes), which may aid progress in genetic studies. In addition, understanding the neuroanatomical correlates of neuropsychological deficits may give insights into the aetiology of autism and ASDs. In neuropsychological terms, three main theories of autism currently exist and each postulates a core impairment that is argued to account for some of the defining behavioural features of autism.

1. Executive dysfunction hypothesis. The executive dysfunction hypothesis of autism holds that deficits in executive control over behaviour account for the defining behavioural features of autism (Turner, 1999a, 1999b). This theory addresses the restricted, repetitive, stereotyped patterns of behaviour characteristic of autism. This theory suggests that due to anatomical dysfunction within the fronto-striatal and fronto-parietal circuits, people with autism will demonstrate difficulties with higher-order cognitive functions, such as sustained attention, response inhibition and cognitive flexibility (Pennington \& Ozonoff, 1996; Verte, Geurts, Roeyers, Oosterlaan, \& Sergeant, 2005).

2. Empathising-systematising theory of autism. This hypothesis outlines abnormal psychological functions that may explain the social and communication deficits characteristic of autism (Baron-Cohen, 2002). This theory postulates that ASD involves deficits in the normal development of empathy. The term 'empathising' encompasses two concepts. First, it includes 'theory of mind' - a person's intuitive ability to understand other people's plans, thoughts, points of view, beliefs, attitudes and emotions. Second, 'empathising' refers to an individual's ability to respond to another person's emotion in an appropriate way. Researchers have suggested that a deficit in empathising underlies the core social and communication impairments characteristic of autism (Baron-Cohen, 1988; Tager-Flusberg, 1993). The term 'systematising' refers to the drive to analyse, explore and construct systems. It is proposed that systematising in autism is either intact or superior (Baron-Cohen, Richler, Bisarya, Gurunathan, \& Wheelwright, 2003; Lawson, Baron-Cohen, \& Wheelwright, 2004). There is fairly robust evidence supporting this theory (Baron-Cohen, 1996; Baron-Cohen, TagerFlusberg, \& Cohen, 1993).

3. While there have been a limited number of studies investigating the links between the postulated cognitive deficit in empathising and structural and functional brain abnormalities, lesion studies and structural and functional neuroimaging studies have suggested that 
abnormalities of the amygdala may underlie the deficit in empathising (Baron-Cohen et al., 2000). Neuroimaging studies, however, have also implicated a number of other brain areas including the medial frontal cortex, orbital frontal cortex and superior temporal sulcus (BaronCohen et al., 1994; Gervais et al., 2004; Happe, 1996). In summary, there is behavioural and physiological evidence for a deficit in empathising in autism and this theory can account for the social-communication deficit in autism.

4. Weak central coherence hypothesis. Frith and Happe (1994) argue that individuals with autism exhibit 'weak central coherence'. The concept of central coherence refers to an informationprocessing style-where incoming information is processed in its context. In weak central coherence (Frith, 1989; Frith \& Happe, 1994; Happe, 1996), information is processed in a piecemeal way, at the expense of contextual meaning. There is an inability to integrate information into a meaningful whole. This hypothesis can account for the unusual attentional features seen in autism; for example fascination with unusual objects or unusual aspects of objects. These results can also explain the experimental findings of abnormal assets and deficits on non-social tasks in individuals with autism (e.g. superior performance on the Embedded Figures Task; Shah \& Frith, 1983, 1993) but poor performance on reading homographs (words with same spelling but two meanings) in context (Frith \& Snowling, 1983; Happe, 1997; Jolliffe \& Baron-Cohen, 1999). However, the neurological abnormalities underpinning weak central coherence are not well understood. There are only a handful of studies investigating the brain basis for this cognitive deficit (e.g. Manjaly et al., in press; Ring et al., 1999). A great deal of neuroanatomical research is needed in this area (Hill \& Frith, 2003).

Evidence has accumulated for each of these theories, and they need not be viewed as competitive (Hill \& Frith, 2003). Each approach attempts to explain discrete aspects of the autistic profile. Characterisation of the neuropsychological deficits postulated by each of the hypotheses may aid identification of diagnostic signs of autism and allow isolation of endophenotypes, which will assist future genetic studies. Over the past decade, there have been limited attempts to understand the neural correlates of these cognitive and behavioural deficits. Only a handful of studies have investigated links between these deficits and brain structure and function. Future interdisciplinary research between neuroimaging and neuropsychology may result in identification of brain abnormalities specific to autism.

This review article concentrates on the executive dysfunction theory of autism and provides a review of research in four specific executive functions in individuals with high-functioning autism.

\subsection{Executive dysfunction in ASD}

Executive functions control, regulate and manage lower-order cognitive processes (Alvarez \& Emory, 2006; Pennington et al., 1997). These higher-order executive functions include processes such as planning and sequencing, working memory, attention, reasoning, inhibition of inappropriate and selection of appropriate behaviours. Deficits in executive function will impact on the functioning of lower-order cognitive processes such as language, perception, explicit memory, learning and action. Intact executive function is needed in order to succeed at nonroutine problem-solving tasks that require flexible thinking and the generation of novel solution strategies.

Over the past two decades, neuropsychological research has provided evidence supporting the executive dysfunction theory of autism (see Pennington \& Ozonoff, 1996 for a review) and the 
link between deficits in executive function and the clinical symptoms of ASD (Hill \& Bird, 2006). It has been proposed that executive function deficits are the underlying cause of core autistic symptoms of perseveration, rule-bound behaviours and obsessionality (Turner, 1999a). Researchers have also shown correlations between executive dysfunction and brain abnormalities recognised in ASD. One of the most prominent brain regions implicated in executive function is the frontal cortex and its connections to striatal and parietal brain regions (Baddeley, 2002; Pennington \& Ozonoff, 1996; Schroeter, Zysset, Wahl, \& von Cramon, 2004; Shallice, 2004).

Children with autism have abnormally large frontal lobes (Carper \& Courchesne, 2000, 2005). This may reflect a lack of synaptogenesis early in life (Belmonte et al., 2004). Substantial evidence suggests that fronto-striatal pathways are abnormal in autism. In adults with ASD, fronto-striatal pathways are reported to be anatomically (Abell et al., 1999; Carper \& Courchesne, 2005; Courchesne et al., 2001; McAlonan et al., 2002; Voelbel, Bates, Buckman, Pandina, \& Hendren, 2006), metabolically (Murphy et al., 2002) and functionally (Silk et al., 2006) abnormal compared with controls.

Reduced fronto-parietal functional connectivity has been reported in individuals with high functioning autism during a task of executive function (Just, Cherkassky, Keller, Kana, \& Minshew, in press). Debate, however, centres on whether anatomical and functional abnormalities exist in autism in the parietal cortex (Abell et al., 1999; Courchesne, Press, \& Yeung-Courchesne, 1993; Hendry et al., 2006; Koshino et al., 2005; McAlonan et al., 2002; Schmitz et al., 2006). During a set shifting and response inhibition task, adults with autism showed increased activation of the frontal and parietal cortices, compared with controls, despite showing normal behavioural performance on these tasks (Schmitz et al., 2006). Thus, alternative, compensatory mechanisms may exist in people with autism, particularly in the inferior and orbitofrontal cortices (Schmitz et al., 2006).

A wide range of executive function deficits have been described in ASD including abnormalities in set shifting (e.g. Verte et al., 2005), planning (e.g. Hughes, Russell, \& Robbins, 1994; Ozonoff \& Jensen, 1999), working memory (e.g. Steele,-, Minshew, Luna, \& Sweeney, in press, , response inhibition (e.g. Hughes \& Russell, 1993; Ozonoff, Strayer, McMahon, \& Filloux, 1994; Russell, Mauthner, Sharpe, \& Tidswell, 1991), and different forms of attention; (e.g. orienting attention; Townsend et al., 1999; Townsend, Courchesne, \& Egaas, 1996; Townsend, Harris, \& Courchesne, 1996), shifting attention (e.g. Rinehart, Bradshaw, Moss, Brereton, \& Tonge, 2006)). This review concentrates on four executive function deficits in ASD—sustained attention, orienting attention, response inhibition and set shifting/cognitive flexibility. Clear correlates between deficits in these executive functions in ASD and clinical presentation will be described. The aim of this review was to investigate the evidence for any putative link between the neuropsychological deficits, neuroanatomical abnormalities and aspects of the clinical phenotype.

\section{Methods}

Medline and Embase searches were carried out using the search terms autism, autism spectrum disorder, neuropsychology, executive function, sustained attention, orienting attention, response inhibition, set shifting, cognitive flexibility, functional magnetic resonance imaging, structural and functional neuroimaging. Articles identified following this initial search were reviewed and relevant articles referenced in these papers were selected. In addition, experts in the field of autism, neuropsychology and neuroimaging were consulted to discuss the review findings and identify other relevant publications. 


\section{Results}

A review of the literature on sustained attention, orienting attention, response inhibition and set shifting in ASD has been provided. Included is a description of the clinical correlates of these executive function deficits, an overview of the research investigating these neuropsychological functions in ASD and a discussion of current knowledge of the neural correlates of these specific executive functions. The need for ongoing research in this area is illustrated. In particular, the need for research linking neuropsychological deficits with neuroanatomical abnormalities is highlighted.

\subsection{Sustained attention}

Sustained attention is a self-directed process, in which a person sustains a mindful, conscious processing of stimuli, whose repetitive, non-arousing qualities would otherwise lead to habituation and distraction (Robertson, Manly, Andrade, Baddeley, \& Yiend, 1997).

\subsubsection{Clinical correlates}

Children with autism have unusual attentional capacities. They have difficulty in attending to stimuli on demand, but may have the ability to focus for hours on unusual aspects of their environment.

\subsubsection{Neuropsychological studies}

There are few studies investigating sustained attention in ASD, partly because it has been difficult to find sensitive tools with which to measure this phenomenon. Tests of sustained attention conventionally involve long periods of monitoring a stream of information for the occurrence of a particular, rarely occurring target. An example is the continuous performance task (CPT). Deteriorating performance over time, rather than absolute levels of accuracy, have generally formed the key index of 'sustained attention' capacity in these studies (Parasuraman, Mutter, \& Molloy, 1991). Most studies performed on people with ASD have reported no deficits in sustained attention (Buchsbaum et al., 1992; Garretson, Fein, \& Waterhouse, 1990; Johnson et al., in press; Noterdaeme, Amorosa, Mildenberger, Sitter, \& Minow, 2001; Pascualvaca, Fantie, Papageorgiou, \& Mirsky, 1998; Siegel, Nuechterlein, Abel, Wu, \& Buchsbaum, 1995; Voelbel et al., 2006); but see (Corbett \& Constantine, 2006).

\subsubsection{Imaging studies}

Neuroimaging studies have begun to illustrate which parts of the brain are involved in the control of sustained attention. One task, the sustained attention to response task (SART) activates the right fronto-parietal attentional network (Manly et al., 2003) that is hypothesised to be dysfunctional in autism (Hendry et al., 2006). There have been no activation studies using the SART, the CPT or any other measure of sustained attention, to investigate the pattern of cortical activation in individuals with autism. Given the neuroanatomical debate as to whether the parietal cortex is implicated in autism, it would be valuable to examine function of the frontal and parietal cortices during a sustained attention task with people with ASD, to determine if activation levels are normal and if there are compensatory mechanisms occurring, despite normal performance in behavioural testing, as found in other tests of executive function (Schmitz et al., 2006). 


\subsection{Orienting attention}

Attention orienting involves three stages: disengaging attention, shifting attention and re-engaging attention (Posner \& Peterson, 1990).

\subsubsection{Clinical correlates}

Children with autism appear to have difficulty disengaging their gaze from an object or activity. This clinical observation has led to numerous studies of autistic individuals investigating their ability to disengage and shift visual attention. The characteristic atypical gaze is considered by many to be an integral part of the social-communication deficit of autism (e.g. Phillips, Baron-Cohen, \& Rutter, 1992).

\subsubsection{Neuropsychological studies}

Over the past decade, the evidence for a deficit in orienting attention in autism has been accumulating (Casey, Gordon, Mannheim, \& Rumsey, 1993; Courchesne et al., 1994; Townsend et al., 1999; Townsend, Harris, et al., 1996; Wainwright \& Bryson, 1996; Wainwright-Sharp \& Bryson, 1993). In 2002, Landry and Bryson again demonstrated that young children with autism had impaired disengagement of attention (Landry \& Bryson, 2004). Rinehart et al have reported a deficit specifically in shifting attention in high functioning autism but not Asperger's disorder (Rinehart, Bradshaw, Moss, Brereton, \& Tonge, 2001). Recent results of research by Renner et al. again support the hypothesis that there are deficits in attention orienting in ASD (Renner, Grofer Klinger, \& Klinger, 2006).

There is also extensive evidence to suggest a role for the cerebellum in dysfunctional attention orienting. An impairment of shifting attention has been reported in both individuals with autism and in patients with acquired cerebellar damage (Akshoomoff \& Courchesne, 1992, 1994). In a number of studies in the early 1990s, Townsend et al reported that patients with damage to the cerebellum are also slow to orient visual attention in space (Townsend, Courchesne, \& Egass, 1992; Townsend, Courchesne, et al., 1996, Townsend, Harris, et al., 1996).

There also appears to be an interesting relationship between the cue type that is shown and ability to orient attention. Children with ASD shift their attention more slowly when the cue has a social component (Dawson, Meltzoff, Osterling, Rinaldi, \& Brown, 1998; Senju, Tojo, Dairoku, \& Hasegawa, 2004). This demonstrates a complex interaction between social awareness and attention function, which is a growing field in neuroscience.

Iarocci and Burack (2004), however, reported findings that are inconsistent with the view that orienting is generally impaired in children with autism. They demonstrated that covert orienting responses to peripheral cues among children with autism were normal (Iarocci \& Burack, 2004). Leekam, Lopez, and Moore (2000) also failed to find a deficit in shifting attention in autism and actually found that the children with autism were faster overall in orienting to targets (Leekam et al., 2000). These disparate findings need further research.

\subsubsection{Imaging studies}

No imaging studies have investigated attention orienting in the ASD population. In normal healthy populations, anatomical and functional areas of the brain linked to attention orienting have been investigated. The orienting system for visual events has been associated with posterior brain areas, including the superior parietal lobe and temporal parietal junction, and in addition, the frontal eye elds (Corbetta \& Shulman, 2002). Functional magnetic resonance imaging studies have suggested that the superior parietal lobe is associated with orienting following the 
presentation of a cue (Corbetta \& Shulman, 2002). Lesions of the temporal parietal junction lobe and superior temporal lobe have also been consistently related to difficulties in orienting (Karnath, Ferber, \& Himmelbach, 2001).

In an interesting study, Townsend et al. (1999) showed that individuals with greater hypoplasia of cerebellar vermal lobules VI-VII had more severe attention-orienting deficits. Evidence from two different tasks performed during the study suggested that slowed spatial attention orienting is associated with structural cerebellar abnormality (Townsend et al., 1999). Harris, Courchesne, Townsend, Carper, and Lord (1999) suggested that the degree of slowed attention orienting to visual cues in children with autism was associated with the degree of cerebellar hypoplasia (Harris et al., 1999).

Courchesne has suggested a putative role for the cerebellum in attention. The cerebellum may continuously track sensory, cognitive and motor information and it relays this information to other brain systems. This may then optimise attentional responses (Courchesne, 1997; Courchesne \& Allen, 1997).

\subsection{Response inhibition}

Response inhibition refers to the ability to suppress irrelevant or interfering stimuli or impulses. This executive function is critical for normal human behaviour.

\subsubsection{Clinical correlates}

Difficulties with inhibitory control of behaviour have been linked to the repetitive, stereotyped patterns of behaviour, which are core diagnostic features of autism (Turner, 1999a). Turner proposes that children with autism become 'locked into' repetitive behavioural patterns because they are unable to inhibit prepotent responding (Turner, 1999b).

\subsubsection{Neuropsychological studies}

Researchers investigating response inhibition in ASD have yielded conflicting results. Individuals with ASD reportedly are unimpaired on classic tasks of inhibition such as the Stroop test (Goldberg et al., 2005; Ozonoff \& Jensen, 1999), tests of negative priming, the stop signal paradigm (Ozonoff \& Strayer, 1997), and neutral inhibition of a Go-NoGo task(Ozonoff \& McEvoy, 1994). In a test of neutral inhibition, participants must always respond to the same 'go' signal, for example subjects are requested to always respond (e.g. via button press) to one particular cue (e.g. ' $x$ '), and to always withhold on another cue (e.g. 'y'). When prepotent inhibition is tested however, where subjects must change their primed response pattern to respond to the stimulus that was the opposite of the initial 'go' stimulus (e.g. press on ' $y$ ' instead of ' $x$ '), autistic individuals perform poorly in comparison with controls. Using a number of paradigms-Go-NoGo task (Ozonoff \& McEvoy, 1994), the Windows task (Russell et al., 1991), the SART (Johnson et al., in press), oculomotor antisaccade task (Luna, Doll, Hegedus, Minshew, \& Sweeney, 2007) and the Detour reaching task (Hughes \& Russell, 1993), deficits in inhibiting prepotent responses have been demonstrated in ASD.

Biro and Russell offer an alternative explanation for these difficulties in response inhibition. They propose that individuals with autism have difficulties in following arbitrary procedures and suggest that it is this obstacle that causes apparent deficits in tasks of inhibition and other executive function tasks (Biro \& Russell, 2001). This theory may suggest impairment in maintaining task-set or goals. 
Russell, Jarrold, and Hood (1999), however, noted that performance on a task of response inhibition may depend on the verbal demands of the task. Even if a task is non-verbal, the individual can improve their performance by using 'inner speech' to explain the task. Individuals with autism may find this difficult (Russell et al., 1999). Bishop and Norbury tested children with HFA, pragmatic language impairment, specific language impairment and controls using two tasks of response inhibition. The authors report that inhibitory deficits were not specific to autism, nor were they linked to particular autistic symptoms. They suggest that inhibitory deficits in ASD may not be associated with autistic symptomatology, but rather with co-morbid attentional deficits and structural language difficulties (Bishop \& Norbury, 2005).

An interesting study published by Wisdom, Dyck, Piek, Hay, and Hallmayer (in press), compared children with autistic disorder, mixed receptive expressive language disorder (RELD) and developmental coordination disorder on a number of measures including response inhibition. The authors report that the RELD group had poorer response inhibition than the group with autistic disorder (Wisdom et al., in press). This study again suggests the importance of language in response inhibition.

However, in the Johnson study, when the children with HFA were tested on the Fixed SART, in which the response inhibition component was minimal, the children with HFA performed the tasks in a similar manner to controls. When the response inhibition component was increased through a randomised presentation of stimuli, the number of commission errors (press on the nogo stimuli) significantly increased compared with controls. The demand on the individual's language ability was similar between the fixed and random versions off the task thus suggesting a response inhibition deficit in high functioning autism (Johnson et al., in press).

\subsubsection{Imaging studies}

Only one study has been published investigating brain function during tasks of response inhibition in autism (Schmitz et al., 2006). In this study, the authors examined whether brain regions that were functionally different were also anatomically abnormal. Despite no significant differences between individuals with ASD and controls in task performance, they found that the ASD group showed significantly increased brain activation in left inferior and orbital frontal gyrus (with motor inhibition (Go-NoGo) tasks), left insula (with interference inhibition (Stroop) tasks) and right inferior and left mesial parietal cortex (during a set shifting and response inhibition (Switch) task). In addition, increased frontal grey matter density and increased functional activation shared the same anatomical location. This finding is interesting given that right prefrontal brain regions have been shown to mediate inhibitory control in normal healthy adults (Garavan, Hester, Murphy, Fassbender, \& Kelly, 2006; Rubia et al., 2005). The authors suggest that the increased activation in the left hemisphere during the Go-NoGo task may reflect a compensatory strategy to achieve correct inhibitory performance. While this study failed to show a deficit in response inhibition in individuals with autism, it reports novel functional imaging findings. Based on previous research findings, a deficit in prepotent inhibition would be expected in individuals with ASD. Brain activation during abnormal inhibition has not been described yet in participants with ASD; however, if challenged with a more demanding task, performance differences may be revealed and activation differences may then be observed.

\subsection{Set shifting}

Set shifting or cognitive flexibility refers to the ability to shift to a different thought or action according to changes in a situation. 


\subsubsection{Clinical correlates}

Both Ridley and Turner have suggested that restrictive, repetitive behaviours in autism are more severe forms of the tendency to perseverate and are possibly due to the inability to generate novel solutions or to shift one's cognitive set (Ridley, 1994; Turner, 1999a, 1999b)

\subsubsection{Neuropsychological studies}

Deficits in set shifting have been consistently reported in ASD. One test of set shifting is the Wisconsin card sort test (WCST) (Heaton, Chelune, Talley, Kay, \& Curtiss, 1993). Numerous researchers have shown that individuals with autism are highly perseverative in their response to the WCST compared with controls (Bennetto, Pennington, \& Rogers, 1996; Ozonoff, 1995; Ozonoff \& McEvoy, 1994; Ozonoff, Pennington, \& Rogers, 1991; Prior \& Hoffmann, 1990; Rumsey \& Hamburger, 1988; Shu, Lung, Tien, \& Chen, 2001; Szatmari, Bartolucci, Bremner, Bond, \& Rich, 1989). Over the past 3 years there have been a number of large studies published, which have reliably demonstrated significant deficits in set shifting in ASD (Geurts, Verte, Oosterlaan, Roeyers, \& Sergeant, 2004; Kenworthy et al., 2005; Ozonoff et al., 2004; Verte et al., 2005).

As in the case of response inhibition, however, there is a question about the role of language in performance of set shifting tasks. In an interesting study published in 2001, Liss et al. demonstrated that although individuals with ASD appear to perseverate more than individuals with developmental language disorder on the WCST, there is actually no significant difference in perseverative errors when verbal IQ is controlled for. The authors suggest that the deficits in set shifting may be related more to verbal skills than to autistic symptoms (Liss et al., 2001).

\subsubsection{Imaging studies}

With regard to investigation of the neural correlates of set shifting, there is only one neuroimaging study investigating brain activity during a task of set shifting in individuals with ASD; as discussed above in relation to response inhibition (Schmitz et al., 2006). The authors did not show a deficit in set shifting on this task in contrast to the majority of previous research outlined above, but did report imaging abnormalities in the parietal cortex during the task. Based on the extensive previous research, a deficit in set shifting in individuals with ASD would be expected. No functional neuroimaging study has investigated brain activity during abnormal set shifting in ASD but again, as discussed in relation to response inhibition, brain activation differences may be observed if more demanding tasks of set shifting reveal a performance deficit in the ASD group.

\section{Discussion}

This article has addressed four specific executive functions. Deficits in three of the four executive functions have clear correlates in the symptoms associated with ASD. In review, there is extensive evidence for deficits in set shifting and orienting of attention in ASD. Studies investigating response inhibition have yielded conflicting results, with some authors reporting a deficit in prepotent inhibition, but others arguing that language and attention deficits may explain these findings. Research on sustained attention is very limited in the ASD population and is suggestive of normal functioning. In total, there is a striking lack of research attempting to understand the neural correlates of these abnormal executive functions. 
This lack of research relating executive dysfunction with neuro-anatomy and function is mirrored in the two other major theories explaining ASD. While there is extensive evidence supporting the empathising-systematising hypothesis (Baron-Cohen, 1996; Baron-Cohen et al., 1993) and the postulated deficits in empathising can account for the core clinical deficits in social behaviour and communication in ASD (Baron-Cohen, 1988; Tager-Flusberg, 1993), there is limited research attempting to understand links between these cognitive deficits and brain structure and function. Likewise, in the weak central coherence hypothesis, although the theory can account for a number of clinical features of autism, the neurological basis of this cognitive deficit has not been well studied. A great deal of neuroanatomical research is needed in this area (Hill \& Frith, 2003).

The executive dysfunction hypothesis of ASD provides a neuroanatomical and functional framework on which to draw hypotheses for future research. In particular, the Posner trinetwork theory of attention might be a very useful model with which to research further the potential executive dysfunctions in ASD. This theory suggests that three attention networks exist within the human brain, each with a separate function (Posner \& Peterson, 1990; Posner, Sheese, Odludas, \& Tang, 2006). The "alerting" network acquires and maintains an alert and vigilant state; the "orienting" network selects information from sensory information and the "executive attention" network resolves conflict that arises between potential responses (Posner \& Rothbart, 2006). The alerting network is thought to involve the right frontal and parietal cortices and the locus coeruleus. The sustained attention ability seen from the review suggests that this alerting network may be intact in participants with ASD. The orienting network is hypothesised to involve the superior parietal, temporal parietal junction, frontal eye fields and the superior colliculus. There is also evidence to suggest that the cerebellum may play a role in attention orienting. Difficulties in orienting attention, as seen in the studies reviewed, suggests that this network is dysfunctional in ASD. The executive attention network is postulated to include the anterior cingulate, lateral ventral and prefrontal cortices and the basal ganglia. Dysfunction in the ability to inhibit primed responses and to mentally shift set, according to a change in rule structure, may be related to dysfunction within this network.

A better understanding of the elements of executive dysfunction in ASD may aid development of effective therapies for this debilitating disorder. For example, it has been suggested that children with ASD may use compensatory mechanisms to normalise their performance on certain executive function tasks (Schmitz et al., 2006). If it were possible to determine the specific compensatory operations they utilise, it may be possible to develop therapies that teach these methods, especially to other neurodevelopmental disorders (e.g. attention deficit hyperactivity disorder).

To reiterate the view of Dawson et al. (2002), it is essential that future research attempting to elucidate the cause of autism integrates findings from genetics, cognitive neuroscience and animal and clinical studies. The review above specifically highlights the need to combine neuropsychological and neuroimaging findings; using both structural and functional neuroimaging to examine the links between executive dysfunction and cortical brain abnormalities. It is hoped that such a modal approach will not only lead to an improved understanding of the neurobiology of autism, but will also allow progress in genetic research through definition of autism-specific cognitive (endo)phenotypes (Dawson et al., 2002).

\section{Uncited reference}

Jolliffe and Baron-Cohen (1997). 


\section{Acknowledgements}

The work herein was supported by grants from the Health Research Board of Ireland and the National Alliance for Autism Research (LG). KAJ is supported by the Health Research Board of Ireland.

\section{References}

Abell, F., Krams, M., Ashburner, J., Passingham, R., Friston, K., Frackowiak, R., et al. (1999). The neuroanatomy of autism: A voxel-based whole brain analysis of structural scans. Neuroreport, 10, 1647-1651.

Akshoomoff, N., \& Courchesne, E. (1992). A new role for the cerebellum in cognitive operations. Behavioural Neuroscience, 106, 731-738.

Akshoomoff, N., \& Courchesne, E. (1994). ERP evidence for a shifting attention deficit in patients with damage to the cerebellum. Journal of Cognitive Neuroscience, 6, 388-399.

Alvarez, J. A., \& Emory, E. (2006). Executive function and the frontal lobes: A meta-analytic review. Neuropsychology Review, 16, 17-42.

Baddeley, A. (2002). Fractionating the central executive. In D. T. Stuss \& R. T. Knight (Eds.), Principles of Frontal Lobe Function (pp. 246-260). New York: Oxford University Press.

Bailey, A., Lecoutteur, A., Gottesman, I., Bolton, P., Simonoff, E., Yuzda, E., et al. (1995). Autism as a strongly genetic disorder-Evidence from a British twin study. Psychological Medicine, 25, 63-77.

Baron-Cohen, S. (1988). Social and pragmatic deficits in autism: Cognitive or affective? Journal of Autism \& Developmental Disorders, 18, 379-402.

Baron-Cohen, S. (1996). Mindblindness: An essay on autism and theory of mind. Massachusetts: MIT Press.

Baron-Cohen, S. (2002). The extreme male brain theory of autism. Trends in Cognitive Sciences, 6, $248-254$.

Baron-Cohen, S., Richler, J., Bisarya, D., Gurunathan, N., \& Wheelwright, S. (2003). The systemizing quotient: An investigation of adults with Asperger syndrome or high-functioning autism, and normal sex differences.. Philosophical Transactions of the Royal Society of London. Series B, Biological Sciences, 358, 361-374.

Baron-Cohen, S., Ring, H. A., Bullmore, E. T., Wheelwright, S., Ashwin, C., \& Williams, S. C. (2000). The amygdala theory of autism. Neuroscience of Biobehavioural Review, 24, 355-364.

Baron-Cohen, S., Ring, H., Moriarty, J., Schmitz, B., Costa, D., \& Ell, P. (1994). Recognition of mental state terms. Clinical findings in children with autism and a functional neuroimaging study of normal adults. British Journal of Psychiatry, 165, 640-649.

Baron-Cohen, S., Tager-Flusberg, H., \& Cohen, D. (1993). Understanding other minds: Perspectives from autism. Oxford: Oxford University Press.

Belmonte, M. K., Cook, E. H. J., Anderson, G. M., Rubenstein, J. L., Greenough, W. T., Beckel-Mitchener, A., et al. (2004). Autism as a disorder of neural information processing: Directions for research and targets for therapy. Molecular Psychiatry, 9, 646-663.

Bennetto, L., Pennington, B., \& Rogers, S. (1996). Intact and impaired memory functions in autism. Child Development, 67, 1816-1835.

Biro, S., \& Russell, J. (2001). The execution of arbitrary procedures by children with autism. Developmental Psychopathology, 13, 97-110.

Bishop, D. V., \& Norbury, C. F. (2005). Executive functions in children with communication impairments, in relation to autistic symptomatology. 2. Response inhibition. Autism, 9, 29-43.

Buchsbaum, M. S., Siegel, B. V., Jr., Wu, J. C., Hazlett, E., Sicotte, N., Haier, R., et al. (1992). Brief report: Attention performance in autism and regional brain metabolic rate assessed by positron emission tomography. Journal of Autism \& Developmental Disorders, 22, 115-125.

Carper, R. A., \& Courchesne, E. (2000). Inverse correlation between frontal lobe and cerebellum sizes in children with autism. Brain, 123(Pt 4), 836-844.

Carper, R. A., \& Courchesne, E. (2005). Localized enlargement of the frontal cortex in early autism. Biological Psychiatry, 15, 126-133.

Casey, B. J., Gordon, C. T., Mannheim, G. B., \& Rumsey, J. M. (1993). Dysfunctional attention in autistic savants. Journal of Clinical and Experimental Neuropsychology, 15, 933-946.

Corbett, B. A., \& Constantine, L. J. (2006). Autism and attention deficit hyperactivity disorder: Assessing attention and response control with the integrated visual and auditory continuous performance test. Child Neuropsychology, 12, $335-348$. 
Corbetta, M., \& Shulman, G. L. (2002). Control of goal-directed and stimulus-driven attention in the brain. Nature Reviews Neuroscience, 3, 201-215.

Courchesne, E. (1997). Prediction and preparation: Anticipatory role of the cerebellum in diverse neurobehavioural functions. Behavioural Brain Science, 20, 248-249.

Courchesne, E., \& Allen, G. (1997). Prediction and preparation, fundamental functions of the cerebellum. Learning and Memory, 4, 1-35.

Courchesne, E., Karns, C. M., Davis, H. R., Ziccardi, R., Carper, R. A., Tigue, Z. D., et al. (2001). Unusual brain growth patterns in early life in patients with autistic disorder: An MRI study. Neurology, 57, 245-254.

Courchesne, E., Press, G. A., \& Yeung-Courchesne, R. (1993). Parietal lobe abnormalities detected with MR in patients with infantile autism. American Journal of Roentgenology, 160, 387-393.

Courchesne, E., Townsend, J., Akshoomoff, N. A., Saitoh, O., Yeung-Courchesne, R., Lincoln, A. J., et al. (1994). Impairment in shifting attention in autistic and cerebellar patients. Behavioral Neuroscience, 108, 848-865.

Dawson, G., Meltzoff, A. N., Osterling, J., Rinaldi, J., \& Brown, E. (1998). Children with autism fail to orient to naturally occurring social stimuli. Journal of Autism and Developmental Disorders, 28, 479-485.

Dawson, G., Webb, S., Schellenberg, G. D., Dager, S., Friedman, S., Aylward, E., et al. (2002). Defining the broader phenotype of autism: Genetic, brain, and behavioral perspectives. Developmental Psychopathology, 14, 581-611.

Fombonne, E. (2003). Epidemiological surveys of autism and other pervasive developmental disorders: An update. Journal of Autism \& Developmental Disorders, 33, 365-382.

Frith, U. (1989). Autism: Explaining the enigma. Oxford: Blackwell Science.

Frith, U., \& Happe, F. (1994). Autism: Beyond "theory of mind". Cognition, 50, 115-132.

Frith, U., \& Snowling, M. (1983). Reading for meaning and reading for sound in autistic and dyslexic children. Journal of Developmental Psychology, 1, 329-342.

Garavan, H., Hester, R., Murphy, K., Fassbender, C., \& Kelly, C. (2006). Individual differences in the functional neuroanatomy of inhibitory control. Brain Research, 1105, 130-142.

Garretson, H. B., Fein, D., \& Waterhouse, L. (1990). Sustained attention in children with autism. Journal of Autism and Developmental Disorders, 20, 101-114.

Gervais, H., Belin, P., Boddaert, N., Leboyer, M., Coez, A., Sfaello, I., et al. (2004). Abnormal cortical voice processing in autism. Nature Neuroscience, 7, 801-802.

Geurts, H. M., Verte, S., Oosterlaan, J., Roeyers, H., \& Sergeant, J. A. (2004). How specific are executive functioning deficits in attention deficit hyperactivity disorder and autism? Journal of Child Psychology and Psychiatry, 45, 836854.

Goldberg, M. C., Mostofsky, S. H., Cutting, L. E., Mahone, E. M., Astor, B. C., Denckla, M. B., et al. (2005). Subtle executive impairment in children with autism and children with ADHD. Journal of Autism \& Developmental Disorders, 35, 279-293.

Happe, F. (1996). Studying weak central coherence at low levels: Children with autism do not succomb to visual illusions. A research note. Journal of Child Psychology and Psychiatry, 37, 873-877.

Happe, F. (1997). Central coherence and theory of mind in autism: Reading homographs in context. British Journal of Developmental Psychology, 15, 1-12.

Harris, N., Courchesne, E., Townsend, J., Carper, R., \& Lord, C. (1999). Neuroanatomic contributions to slowed orienting of attention in children with autism. Cognitive Brain Research, 8, 61-71.

Heaton, R. K., Chelune, G. J., Talley, J. L., Kay, G. G., \& Curtiss, G. (1993). Wisconsin card sorting test manual: Revised and expanded. Florida: Psychological Assessment Resources.

Hendry, J., DeVito, T., Gelman, N., Densmore, M., Rajakumar, N., Pavlosky, W., et al. (2006). White matter abnormalities in autism detected through transverse relaxation time imaging. NeuroImage, 29, 1049-1057.

Hill, E. L., \& Bird, C. M. (2006). Executive processes in Asperger syndrome: Patterns of performance in a multiple case series. Neuropsychologia, 44, 2822-2835.

Hill, E., \& Frith, U. (2003). Understanding autism: Insights from mind and brain. Philosophical Transactions of the Royal Society of London. Series B, Biological Sciences, 358(1430), 281-289.

Hughes, C., \& Russell, J. (1993). Autistic children's difficulty with mental disengagement from an object: It's implications for theories of autism. Developmental Psychology, 29, 298-510.

Hughes, C., Russell, J., \& Robbins, T. W. (1994). Evidence for executive dysfunction in autism. Neuropsychologia, 32, 477-492.

Iarocci, G., \& Burack, J. (2004). Intact covert orienting to peripheral cues among children with autism. Journal of Autism \& Developmental Disorders, 34, 257-264.

International Molecular Genetic Study of Autism Consortium. (2001). A genomewide screen for autism: Strong evidence for linkage to chromosomes 2q, 7q, and 16p. American Journal of Human Genetics, 69, 570-581. 
Johnson, K. A., Robertson, I. H., Kelly, S. P., Silk, T. J., Barry, E., Dáibhis, A., et al. (in press). Dissociation in performance of children with ADHD and autism on a task of sustained attention. Neuropsychologia.

Jolliffe, T., \& Baron-Cohen, S. (1997). Are people with autism and Asperger syndrome faster than normal on the embedded figures test? Journal of Child Psychology and Psychiatry, 38, 527-534.

Jolliffe, T., \& Baron-Cohen, S. (1999). A test of central coherence theory: Linguistic processing in high-functioning adults with autism or Asperger syndrome: Is local coherence impaired? Cognition, 71, 149-185.

Just, M. A., Cherkassky, V. L., Keller, T. A., Kana, R. K., \& Minshew, N. J. (in press), Functional and anatomical cortical underconnectivity in autism: Evidence from an fMRI study of an executive function task and corpus callosum morphometry. Cerebral Cortex,

Karnath, H., Ferber, S., \& Himmelbach, M. (2001). Spatial awareness is a function of the temporal not the posterior parietal lobe. Nature, 411, 950-953.

Kenworthy, L., Black, D., Wallace, G., Ahluvalia, T., Wagner, A., \& Sirian, L. (2005). Disorganization: The forgotten executive dysfunction in high-functioning autism (HFA) spectrum disorders. Developmental Neuropsychology, 28, 809-827.

Koshino, H., Carpenter, P. A., Minshew, N. J., Cherkassky, V. L., Keller, T. A., \& Just, M. A. (2005). Functional connectivity in an fMRI working memory task in high-functioning autism. NeuroImage, 24, 810-821.

Landry, R., \& Bryson, S. (2004). Impaired disengagement of attention in young children with autism. Journal of Child Psychology and Psychiatry, 45, 1115-1122.

Lawson, J., Baron-Cohen, S., \& Wheelwright, S. (2004). Empathising and systemising in adults with and without Asperger syndrome. Journal of Autism and Developmental Disorders, 34, 301-310.

Leekam, S. R., Lopez, B., \& Moore, C. (2000). Attention and joint attention in preschool children with autism. Developmental Psychology, 36, 261-273.

Liss, M., Fein, D., Allen, D., Dunn, M., Feinstein, C., Morris, R., et al. (2001). Executive functioning in high-functioning children with autism. Journal of Child Psychology and Psychiatry, 42, 261-270.

Luna, B., Doll, S. K., Hegedus, S. J., Minshew, N. J., \& Sweeney, J. A. (2007). Maturation of executive function in autism. Biological Psychiatry, 61, 474-481.

Manjaly, Z. M., Bruning, N., Neufang, S., Stephan, K. E., Brieber, S., Marshall, J. C., et al. (in press). Neurophysiological correlates of relatively enhanced local visual search in autistic adolescents. NeuroImage $e_{\overline{\mathrm{Z}}}$

Manly, T., Owen, A. M., McAvenue, L., Datta, A., Lewis, G. H., Scott, S. K., et al. (2003). Enhancing the sensitivity of a sustained attention task to frontal damage: Convergent clinical and functional imaging evidence. Neurocase, 9, 340349.

McAlonan, G. M., Daly, E., Kumari, V., Critchley, H. D., van Amelsvoort, T., Suckling, J., et al. (2002). Brain anatomy and sensorimotor gating in Asperger's syndrome. Brain, 125, 1594-1606.

Murphy, D. G., Critchley, H. D., Schmitz, N., McAlonan, G., Van Amelsvoort, T., Robertson, D., et al. (2002). Asperger syndrome: A proton magnetic resonance spectroscopy study of brain. Archives of General Psychiatry, 59, 885-891.

Noterdaeme, M., Amorosa, H., Mildenberger, K., Sitter, S., \& Minow, F. (2001). Evaluation of attention problems in children with autism and children with a specific language disorder. European Child \& Adolescent Psychiatry, 10, 5866.

Ozonoff, S. (1995). Reliability and validity of the Wisconsin card sorting test in studies of autism. Neuropsychology, 9 , 491-500.

Ozonoff, S., Cook, I., Coon, H., Dawson, G., Joseph, R. M., Klin, A., et al. (2004). Performance on Cambridge neuropsychological test automated battery subtests sensitive to frontal lobe function in people with autistic disorder: Evidence from the collaborative programs of excellence in autism network. Journal of Autism and Developmental Disorders, 34, 139-150.

Ozonoff, S., \& Jensen, J. (1999). Brief report: Specific executive function profiles in three neurodevelopmental disorders. Journal of Autism and Developmental Disorders, 29, 171-177.

Ozonoff, S., \& McEvoy, R. E. (1994). A longitudinal study of executive function and theory of mind development in autism. Developmental Psychopathology, 6, 415-431.

Ozonoff, S., Pennington, B. F., \& Rogers, S. J. (1991). Executive function deficits in high-functioning autistic individuals: Relationship to theory of mind. Journal of Child Psychology and Psychiatry, 32, 1081-1105.

Ozonoff, S., \& Strayer, D. L. (1997). Inhibitory function in nonretarded children with autism. Journal of Autism and Developmental Disorders, 27, 59-77.

Ozonoff, S., Strayer, D. L., McMahon, W. M., \& Filloux, F. (1994). Executive function abilities in autism and Tourette syndrome: An information processing approach. Journal of Child Psychology and Psychiatry, 35, $1015-1032$.

Parasuraman, R., Mutter, S., \& Molloy, R. (1991). Sustained attention following mild closed-head injury. Journal of Clinical \& Experimental Neuropsychology, 13, 789-811. 
Pascualvaca, D. M., Fantie, B. D., Papageorgiou, M., \& Mirsky, A. F. (1998). Attentional capacities in children with autism: Is there a general deficit in shifting focus? Journal of Autism \& Developmental Disorders, 28, 467-478.

Pennington, B. F., \& Ozonoff, S. (1996). Executive functions and developmental psychopathology. Journal of Child Psychology and Psychiatry, 37, 51-87.

Pennington, B., Rogers, S., Bennetto, L., Griffith, E., Reeds, T., \& Shyu, V. (1997). Validity tests of the executive dysfunction hypothesis of autism. Oxford: Oxford University Press.

Phillips, W., Baron-Cohen, S., \& Rutter, M. (1992). The role of eye contact in goal detection: Evidence from normal infants and children with autism and mental handicaps. Development and Psychopathology, 4, 375-383.

Pickles, A., Bolton, P., Macdonald, H., Bailey, A., Le Couteur, A., Sim, C., et al. (1995). Latent-class analysis of recurrence risks for complex phenotypes with selection and measurement error: A twin and family history study of autism. American Journal of Human Genetics, 57, 717-726.

Posner, M. I., \& Peterson, S. E. (1990). The attention system of the human brain. Annual Review of Neuroscience, 13, 3542.

Posner, M. I., \& Rothbart, M. K. (2006). Research on attention networks as a model for the integration of psychological science. Annual Review of Psychology, 58, 1-13.

Posner, M. I., Sheese, B. E., Odludas, Y., \& Tang, Y. (2006). Analyzing and shaping human attentional networks. Neural Networks, 19, 1422-1429.

Prior, M., \& Hoffmann, W. (1990). Brief report: Neuropsychological testing of autistic children through an exploration with frontal lobe tests. Journal of Autism \& Developmental Disorders, 20, 581-590.

Renner, P., Grofer Klinger, L., \& Klinger, M. (2006). Exogenous and endogenous attention orienting in autism spectrum disorders. Child Neuropsychology, 12, 361-382.

Ridley, R. (1994). The psychology of perserverative and stereotyped behaviour. Progress in Neurobiology, 44, $221-231$.

Rinehart, N. J., Bradshaw, J. L., Moss, S. A., Brereton, A. V., \& Tonge, B. J. (2001). A deficit in shifting attention present in high-functioning autism but not Asperger's disorder. Autism, 5, 67-80.

Rinehart, N. J., Bradshaw, J. L., Moss, S. A., Brereton, A. V., \& Tonge, B. J. (2006). Pseudo-random number generation in children with high-functioning autism and Asperger's disorder: Further evidence for a dissociation in executive functioning? Autism, 10, 70-85.

Ring, H. A., Baron-Cohen, S., Wheelwright, S., Williams, S. C., Brammer, M., Andrew, C., et al. (1999). Cerebral correlates of preserved cognitive skills in autism: A functional MRI study of embedded figures task performance. Brain, 122, 1305-1315.

Risch, N., Spiker, D., Lotspeich, L., Nouri, N., Hinds, D., Hallmayer, J., et al. (1999). A genomic screen of autism: Evidence for a multilocus etiology. American Journal of Human Genetics, 65, 493-507.

Robertson, I. H., Manly, T., Andrade, J., Baddeley, B. T., \& Yiend, J. (1997). 'Oops!': Performance correlates of everyday attentional failures in traumatic brain injured and normal subjects Neuropsychologia, 35, 747-758.

Rubia, K., Lee, F., Cleare, A. J., Tunstall, N., Fu, C. H., Brammer, M., et al. (2005). Tryptophan depletion reduces right inferior prefrontal activation during response inhibition in fast, event-related fMRI. Psychopharmacology, 179, 791-803.

Rumsey, J., \& Hamburger, S. (1988). Neuropsychological findings in high-functioning men with infantile autism, residual state. Journal of Clinical \& Experimental Neuropsychology, 10, 201-221.

Russell, J., Jarrold, C., \& Hood, B. (1999). Two intact executive capacities in children with autism: Implications for the core executive dysfunctions in the disorder. Journal of Autism and Developmental Disorders, 29, $103-112$.

Russell, J., Mauthner, N., Sharpe, S., \& Tidswell, T. (1991). The 'Windows' task as a measure of strategic deception in preschoolers and autistic subjects. British Journal of Developmental Psychology, 9, 101-119.

Schmitz, N., Rubia, K., Daly, E., Smith, A., Williams, S., \& Murphy, D. G. (2006). Neural correlates of executive function in autistic spectrum disorders. Biological Psychiatry, 59, 7-16.

Schroeter, M. L., Zysset, S., Wahl, M., \& von Cramon, D. Y. (2004). Prefrontal activation due to Stroop interference increases during development-An event-related fNIRS study. NeuroImage, 23, 1317-1325.

Senju, A., Tojo, Y., Dairoku, H., \& Hasegawa, T. (2004). Reflexive orienting in response to eye gaze and an arrow in children with and without autism. Journal of Child Psychology and Psychiatry, 45, 445-458.

Shah, A., \& Frith, U. (1983). An islet of ability in autistic children: A research note. Journal of Child Psychology and Psychiatry, 24, 613-620.

Shah, A., \& Frith, U. (1993). Why do autistic individuals show superior performance on the block design task? Journal of Child Psychology and Psychiatry, 34, 1351-1364.

Shallice, T. (2004). The fractionation of supervisory control. In M. S. Gazzaniga (Ed.), The Cognitive Neurosciences (3rd ed., pp. 943-956). Cambridge: MIT Press.

Shu, B. C., Lung, F. W., Tien, A. Y., \& Chen, B. C. (2001). Executive function deficits in non-retarded autistic children. Autism, 5, 165-174. 
Siegel, B. V., Jr., Nuechterlein, K. H., Abel, L., Wu, J. C., \& Buchsbaum, M. S. (1995). Glucose metabolic correlates of continuous performance test performance in adults with a history of infantile autism, schizophrenics, and controls. Schizophrenia Research, 17, 85-94.

Silk, T. J., Rinehart, N. J., Bradshaw, J. L., Tonge, B. J., Egan, G. F., O’Boyle, M. W., et al. (2006). Visuospatial processing and the function of prefrontal-parietal networks in autism spectrum disorder: A functional MRI study. American Journal of Psychiatry, 163, 1440-1443.

Steele, S., Minshew, N., Luna, B., \& Sweeney, J. A. (in press), Spatial working memory deficits in autism. Journal of Autism \& Developmental Disorders.

Szatmari, P., Bartolucci, G., Bremner, R., Bond, S., \& Rich, S. (1989). A follow-up study of high-functioning autistic children. Journal of Autism \& Developmental Disorders, 19, 213-225.

Tager-Flusberg, H. (1993). What language reveals about the understanding of minds in children with autism. Oxford: Oxford University Press.

The Autism Genome Project Consortium. (in press). Mapping autism risk loci using genetic linkage and chromosomal rearrangements. Nature Genetics,

Townsend, J., Courchesne, E., Covington, J., Westerfield, M., Harris, N. S., Lyden, P., et al. (1999). Spatial attention deficits in patients with acquired or developmental cerebellar abnormality. Journal of Neuroscience, 19, 5632-5643.

Townsend, J., Courchesne, E., \& Egass, B. (1992). Deficits in orienting attention in patients with cerebellar and parietal damage. Society for Neuroscience Abstracts, 18, 332.

Townsend, J., Courchesne, E., \& Egaas, B. (1996a). Slowed orienting of covert visual-spatial attention in autism: Specific deficits associated with cerebellar and parietal abnormality. Development and Psychopathology, 8, 563-584.

Townsend, J., Harris, N. S., \& Courchesne, E. (1996b). Visual attention abnormalities in autism: Delayed orienting to location. Journal of the International Neuropsychological Society, 2, 541-550.

Turner, M. (1999a). Annotation: Repetitive behaviour in autism: A review of psychological research. Journal of Child Psychology and Psychiatry, 40, 839-849.

Turner, M. (1999b). Generating novel ideas: Fluency performance in high-functioning and learning disabled individuals with autism. Journal of Child Psychology and Psychiatry, 40, 189-201.

Verte, S., Geurts, H. M., Roeyers, H., Oosterlaan, J., \& Sergeant, J. A. (2005). Executive functioning in children with autism and Tourette syndrome. Developmental Psychopathology, 17, 415-445.

Voelbel, G. T., Bates, M. E., Buckman, J. F., Pandina, G., \& Hendren, R. L. (2006). Caudate nucleus volume and cognitive performance: Are they related in childhood psychopathology? Biological Psychiatry, 60, 942-950.

Wainwright, J. A., \& Bryson, S. E. (1996). Visual-spatial orienting in autism. Journal of Autism and Developmental Disorders, 26, 423-438.

Wainwright-Sharp, J. A., \& Bryson, S. E. (1993). Visual orienting deficits in high-functioning people with autism. Journal of Autism and Developmental Disorders, 23, 1-13.

Wisdom, S., Dyck, M., Piek, J. P., Hay, D., \& Hallmayer, J. (in press). Can autism, language and coordination disorders be differentiated based on ability profiles? European Child \& Adolescent Psychiatry. 